\title{
Resource Use Efficiency in Maize Production by Small-Scale Farmers in Two Districts of Mwanza Region, Tanzania
}

\author{
Gongwe, Anne. G. (Corresponding author) \\ Economics Department \\ St. Augustine University of Tanzania \\ Mwanza, Tanzania. \\ Email: abmfilinge@gmail.com
}

Kongolo, M.

Economics Department

St. Augustine University of Tanzania

Mwanza, Tanzania

Email: gilkoka8@gmail.com

Received: May 1, 2020

Accepted: June 8, 2020

Published: June 10, 2020

doi:10.5296/ijrd.v7i1.17162

URL: http://dx.doi.org/10.5296/ijrd.v7i1.17162

\begin{abstract}
This study investigates the resource use efficiency in the production of maize by small-scale farmers in Mwanza region. Specifically, the study seeks to determine what the resources that farmers use in maize production and also seeks to determine the challenges that farmers face in maize production in the study area. This study was conducted in two districts of Mwanza region. In each of the district, the study sampled three wards and randomly selected twelve small-scale farmers from each of the three wards selected. In total 72 small-scale farmers were selected from whom the data was collected. A Cobb-Douglas production function was used to fit and analyse the data for its good fit. The $\mathrm{R}^{2}$ was 0.77 , indicating that 77 percent of the variation in dependent variable was explained by the independent variables of the model. The use of inputs in the production of maize was noted to be increasing returns to scale. The results indicated that variables land $\left(\mathrm{X}_{1}\right)$, labour $\left(\mathrm{X}_{2}\right)$, age $\left(\mathrm{X}_{6}\right)$, and experience $\left(\mathrm{X}_{8}\right)$ were all
\end{abstract}


positive and significant at the $1 \%$ while soil preparation $\left(\mathrm{X}_{4}\right)$ variable was negative but significant at the 5\%. The major constraints to maize production included lack of fertilizer (manure), finance (capital) and access to land. The study concluded that more exposure of small-scale farmers to frequent extension services is important to assist them to produce efficiently.

Keywords: Maize production, small-scale farmers, resource use efficiency, increased productivity, economies of scale, Mwanza, Tanzania.

\section{Introduction}

The Tanzanian agricultural sector which encompasses livestock, forestry, hunting, and fishing, is an important pillar of the country's economy (Adebowale, 2014). The sector accounted for 28 percent of GDP (2010) and 25 percent of export earnings (2011) and it provides a livelihood to more than 75 percent of the population (World Bank, 2015). Agriculture continues to be an important sector that serves as one of the main activities and income sources for majority of rural households. Maize is the most important food crops as it comprises 45 percent of the cultivated area. Though Tanzania is the largest producer of maize in East Africa, the country still faces lots of challenges of achieving full business potential. The country has been ranked among the top 25 maize producing countries in the world for the last two decades (World Bank, 2015). Maize production accounts for more than 70 percent of the cereal produced in the country. The sector has high potential for economic growth and trade expansion, but it has been limited by barriers such as policies, high costs, failure to meet quality requirements and a lack of financial capacity (Match Maker Association, 2014). Maize is the traditional food in both rural and urban areas and rice is increasingly becoming more important in towns as family income tends to rise. Maize is also the most widespread crop among smallholders, and production surpluses are traded to the extent that in good years it may become a relevant cash crop. Agro-ecological conditions for growing maize are good in Tanzania, and normal conditions are better than in neighboring countries. In spite of this, in general productivity in maize remains low (World Bank, 2015).

Most maize, about 80 percent, is produced by small-scale farmers and is grown both for subsistence and as a cash crop. Between 65 percent and 80 percent of all maize is consumed within the producing households, and only some 20 percent to 35 percent enters commercial channels (FAO, 2015). Maize comprises an average of 16 percent of national household food expenditures, though there are big regional variations. In Tanzania, maize is usually grown under low input, rainfed conditions. The choice to grow maize, even in areas of insufficient rainfall, is driven by a strong dietary preference for maize over the more drought-adapted traditional cereals such as sorghum and millet (FAO, 2015). Increase in the productivity of maize is necessary to achieve a minimal level of food security since it is the most popular cereals grown in the country as a whole (Shehu et al., 2017). Maize is an annual crop of great importance used as a source of carbohydrate to both humans and animal feed worldwide, due to its high feeding value and it is also used in production of biofuel (Undie et al., 2012). Studies have been conducted on maize production, but little research has been conducted on resource use efficiency by small-scale maize producers. The present study was, therefore, undertaken to determine the importance of resource use efficiency in maize production based 
on farm size to provide valuable information that may be useful for appropriate policy on maize production by small-scale farmers in the region.

\subsection{The Problem Statement}

Maize is a cereal crop occupying an important position among other cereals such as rice, wheat and sorghum produced in many countries (Shehu et al., 2017). Maize is recognized as a common component in most intercropping system. It has the great potential to lead as the cereal constituent of intercrop and is often combined with dissimilar crops (Memon et al,. 2016; Abdulai et al., 2018). It is equally well accepted for feed ingredient and can contribute up to $30 \%$ protein, $60 \%$ energy, and $90 \%$ starch in animal diet (Shehu et al., 2017). Despite its importance, maize production in Tanzania is predominated by small-scale producers who use traditional methods of production. Because of low yields, up to $80 \%$ of all maize is consumed by the producing households (FAO, 2015; World Bank, 2015).

Changes are needed to help millions of small-scale farmers who currently make little or no profit from maize production to become profitable (Adesoji, et al, 2013; FAO, 2015). Generally, small-scale maize production yields are low. To achieve optimum production level, resources available must be used efficiently (FAO, 2015; World Bank, 2015). Scarce resources are underutilized in addition to the use of low yielding varieties, poor extension services, inadequate incentives and amenities giving rise to low output leading to low farm income (Memon et al., 2016; Abdulai et al., 2018). Resource use efficiency is the only way to increase small-scale maize production outputs. It should be supported by successful planning for needed level of technical knowledge of productivities of farm resources, in order to understand the necessary adjustments in order to achieve the correct input mix (Memon et al, 2016; Shehu et al., 2017; Abdulai et al., 2018). In this regard, Shehu et al., (2017) argued that production strategies require to be formulated to increase small-scale maize production in order to face food shortage in the country. It is expected that in order to help farmers increase production, the focus should be on whether farmers are using better and improved technologies. Tambo and Gbemu (2010) emphasized the necessity to investigate whether farmers are even making maximum use of what is available to them in terms of inputs so that the stakeholders involved in agriculture will be convinced that the new technologies they intend to introduce to farmers will be used efficiently and cost-effectively to boost output.

\subsection{Objectives}

This study was undertaken with the main objective to measure the efficient use of resources utilised in maize production by small-scale farmers in Mwanza region. Specifically:

- to determine the efficient use of resources by small-scale maize producers; and

- $\quad$ to determine constraints to maize production faced by small-scale producers.

\subsection{Research Questions}

The two main research questions addressed in this study were the following:

- What are the main resources and how efficiently are they used by small-scale 


\section{Macrothink}

farmers in maize production?

- How successful small-scale maize producers have achieved increasing returns to scale?

\section{Methodology}

\subsection{Study Area}

The study was conducted in Mwanza, one of Tanzania's 31 administrative regions. The national census of 2012 said the region had a total population of 3,125, 995 (THDR, 2017) with eight district councils, namely: Magu, Ukerewe, Buchosa, Sengerema, Kwimba, Misungwi, Ilemela and Nyamagana (URT, 2017). Region 8 cannot be seen in the map properly. The regional capital Mwanza lies in the northern part of the country, located between latitude $1^{\circ} 30^{\prime}$ and $3^{\circ}$ south of the Equator. Longitudinally the region is located between $31^{\circ} 45^{\prime}$ and $34^{\circ} 10^{\prime}$ east of Greenwich. The region shares borders with Lake Victoria (Figure 1) in the North, Kagera and Geita in the West, Mara Region in the East, while Shinyanga and Simiyu regions are located on the South and South-eastern side of the region.

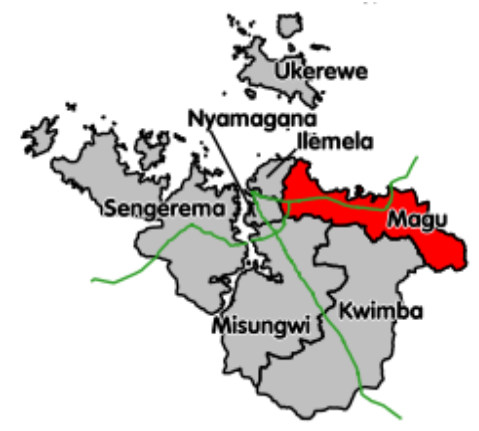

Figure 1. Mwanza regional map

Mwanza is a relatively small region occupying $2.3 \%$ of the total land area of Tanzania mainland. The region occupies a total of 35,187 sq km., out of this area $20,095 \mathrm{sq} \mathrm{km}$ is dry land and $15,092 \mathrm{sq} \mathrm{km}$ is covered by Lake Victoria. The Region's $43 \%$ of surface area is covered by water, the remaining $57 \%$ of surface is a dry land, Figure 2 , Table 1 (URT, 1999).

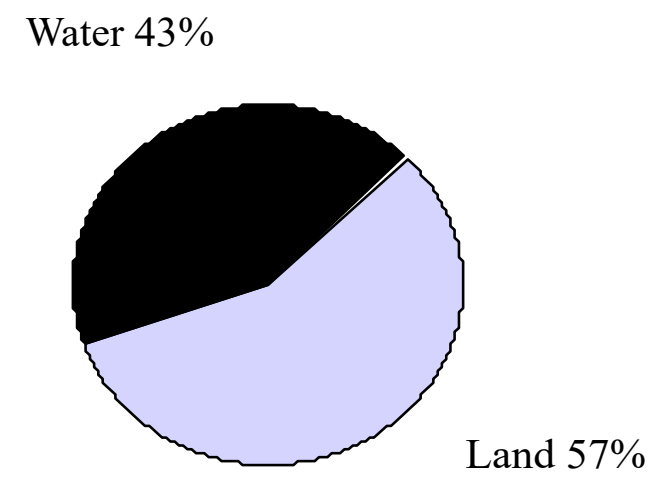

Figure 2: Distribution of surface area, Mwanza region 


\section{Ml Macrothink}

The region's 8 districts including land area ( $\mathrm{sq} \mathrm{km})$, water area $(\mathrm{sq} \mathrm{km})$, total area $(\mathrm{sq} \mathrm{km})$, and total percentage of each district or administrative units are shown in Table 1. The main ethnic groups in Mwanza include the Sukuma, Zinza, Haya, Sumbwa, Nyamwezi, Luo, Kurya, Jita and Kerewe. The Sukuma dominate by constituting over 90 percent of the population. The rest of the groups constitute small proportions.

Table 1. Mwanza Region land area and administrative units

\begin{tabular}{|c|c|c|c|c|}
\hline District & $\begin{array}{l}\text { Dry Land (sq km) } \\
\text { Area }\end{array}$ & Water Area (sq km) & Total Area (sq km) & $\begin{array}{l}\% \text { of Total regional } \\
\text { Area }\end{array}$ \\
\hline Magu & 3,070 & 1,725 & 4,795 & 13.6 \\
\hline Ukerewe & 640 & 5,760 & 6,400 & 18.2 \\
\hline Buchosa & 1,274 & 5,383 & 6,657 & 18.9 \\
\hline Sengerema & 3,335 & 5,482 & 8,817 & 25.1 \\
\hline Kwimba & 3,903 & - & 3,903 & 11.1 \\
\hline Misungwi & 1,947 & 175 & 2,122 & 6.0 \\
\hline Nyamagana & 184.9 & 71.55 & 1,337 & 3.8 \\
\hline Ilemela & 252.10 & 828.45 & 1080 & 3.07 \\
\hline Total & 20,095 & 15,092 & 35,187 & 100 \\
\hline
\end{tabular}

Source: URT, 2017.

Main crops grown in the region include maize, cotton, cassava, coffee, paddy, sweet potatoes and fruits. Chickens, sheep and cattle are also raised for meat and the diet is also supplemented by fish. Small-scale farmers dominate the production of the staple food crops in rural areas (URT, 1999).

\subsection{Data Collection}

Both qualitative and quantitative methods were used in this study. Qualitative methodology was used to describe the perceptions attached to the contributions of the various authors' analysis of the resource use efficiency in maize production (Astalin, 2013), since it represents relatively a cost-effective approach in describing a situation (Corbin \& Strauss, 2008). Secondary data was collected by conducting a review of the literatures of both published and unpublished reports on the topic, which allowed the authors to make effective use of information already available while conceptualizing this assessment, thus being able to focus on quantitative data collection to fill the key information gaps. Primary data was collected with the aid of a well structure questionnaire. The data were collected using multi-stage sampling techniques. The study methodologies were carefully designed to maximize the use of available qualitative and quantitative information (Corbin \& Strauss, 2008). Therefore, both qualitative and quantitative designs were used to achieve the objectives of the study. 


\subsection{Sampling Technique and Data Collection}

The study used multi-stage sampling technique in order to have respondents needed in the study area. As expressed in the study area section, Mwanza region is made up of eight districts. Two districts were purposively selected because if their maize production potential. From the sampled districts three (3) wards per district were randomly selected and 12 small-scale farmers randomly chosen from each of these three selected wards. It resulted in a total of seventy-two (72) participants randomly sampled during the study period. The three selected wards were Usagara, Misungwi and Isesa. The research used both secondary and primary data. Secondary data was gathered from various official reports while primary data was collected from a cross-sectional survey of small-scale maize producers in the region. Data on socioeconomic variables such as age, sex, farm size and farming experience were also collected.

\subsection{Model Specification}

A production technique known as Cobb-Douglas production function was used in this study to examine the efficiency of small-scale maize producer in the study area. This technique was selected on the basis of its best fit and significant result on output (Ferdausi et al, 2014). According to Gujarati (2006), it is the most frequently used technique to describe situations related to economic theory of agricultural production. The specification of the Cobb-Douglas production function in this study was expressed as follows:

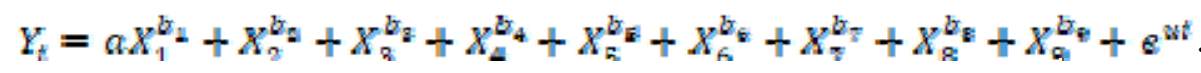

Where $\mathrm{Y}=$ output, $\mathrm{X}_{\mathrm{i}}$ are inputs used

$\mathrm{U}=$ stochastic disturbance term

$\mathrm{e}=$ base of natural logarithm

From the equation (1), it is clear that the relationship between the output and the inputs is a nonlinear. By log-transforming equation (1), a linear stochastic form of the specified Cobb Douglas model was modelled as following in the equation (2) below,

$$
\operatorname{Lnt} X_{t}^{*}-\tan \beta_{1}+\beta_{2} \ln X_{2 t}+\beta_{8} \ln X_{3 t}+\cdots \ldots+\mu_{t}
$$

Where $\beta u-\ln \beta 1$

Equation (2) is linear in the parameters $\beta_{o}, \beta_{2}$, and $\beta_{3}$, therefore it is a linear regression model. It is nonlinear in the variables $\mathrm{Y}$ and $\mathrm{X}$, but it is linear in the logs of the same variables. In the Cobb- Douglas production function $\beta_{1}$ is the (partial) elasticity of the output with respect to the land input, that is, it measures the percentage change in output for, say, a one percentage change in the land input, holding the labour input constant. The sum of $\left(\beta_{1}+\beta_{2}\right)$ gives information about the efficient use of inputs, that is, the response of output to a proportionate change in the inputs. This means that, if the sum of $\left(\beta_{1}+\beta_{2}\right)$ is less than 1 (or $\left.r<1\right)$, there will be 


\section{Macrothink}

decreasing returns to scale, that is, doubling the inputs will result in less than double the output, a sign of inefficiency. If the sum of $\left(\beta_{1}+\beta_{2}\right)$ is greater than 1 (or $r>1$ ), there will be increasing returns to scales, that is, doubling the inputs will be more than double the output, another sign of inefficiency. When the sum of $\left(\beta_{1}+\beta_{2}\right)$ is equals to 1 , that is when the ratio $r$ $=1$, it shows that the resource was efficiently utilized in the production process. This is the best point to maximize profit (Gujarati, 2006). Following Ferdausi et al, (2014), the Cobb-Douglas production function, in its linear form, used in this study was expressed as follows:

$$
\text { Giv } X_{t}-\beta_{0}+\beta_{1} X_{1}+\beta_{2} X_{2}+\beta_{3} X_{3}+\beta_{4} X_{4}+\beta_{6} X_{6}+\beta_{6} X_{6}+\beta_{7} X_{7}+\beta_{8} X_{8}+\beta_{9} X_{9}+\mu_{4}
$$

Where $\mathrm{Y}=$ output value of vegetables in $\mathrm{kg}$ per ha

$\mathrm{X}_{1}=$ Land (man/ha)

$\mathrm{X}_{2}=$ Labour (hour/ha)

$\mathrm{X}_{3}=$ Fertilizer $(\mathrm{kg} / \mathrm{ha})$

$\mathrm{X}_{4}=$ Irrigation $($ liter/ ha $)$

$\mathrm{X}_{5}=$ Seeds $(\mathrm{kg} / \mathrm{ha})$

$\mathrm{X}_{6}=$ Soil preparation input (hour/ha)

$\mathrm{X}_{7}=$ Age of farmer (years)

$\mathrm{X}_{8}=$ Experience (years)

$\mathrm{X}_{9}=$ Educational level (years)

where $\beta v-\epsilon_{t} \beta 1$ in equation (3)

Equation ( 3 ) is linear in the parameters $\beta_{0}, \beta_{1}, \beta_{2}, \ldots \ldots . \beta_{9}$.

The Null hypothesis to be tested is $\mathrm{H}_{0}: \beta=0$ and the alternative hypothesis is $H_{1} 1 \beta_{08} \neq 0_{*}$ If it is found that $\beta$ is significantly greater or less than zero, the null hypothesis, $\mathrm{H} 0$ : $\beta=0$, can be rejected and it can be concluded that the variable impacts the production of maize. A positive (or negative) parameter $(\beta)$ estimate can suggest a higher (or lower) likelihood of an increase in maize production by small-scale producers. These coefficients of equation (3) are also known as the marginal productivities of the corresponding inputs with respect to output (Tambo and Gbemu, 2010). Efficient production of maize requires that in order for resources to be efficiently used and result in the maximum profit the ratio of marginal value product (MVP) to marginal factor cost (MFC) equals one, which is not often the case with small scale producers (Ferdausi et al., 2014). When the marginal physical product (MPP) is multiplied by the product price, it is called marginal value product (MVP). Marginal factor cost is the price of one unit of input. The optimum use of a particular input would be ascertained by the 
equation of equality of MVP and MFC, that is $\mathrm{MVP}_{\mathrm{xi}} / \mathrm{MFC}_{\mathrm{xi}}=1$ (Ferdausi et al., 2014).

\section{Results and Discussion}

This section discusses the study results analyzed by mean of the Statistical Package for the Social Sciences program (SPSS). The analysis of the Cobb-Douglass production function and return to scale efficiency were performed. The efficiency indices were derived from the analysis of the Cobb-Douglas production function in its linear regression model expressed in equation 3. The coefficient of variable Educational level $\left(\mathrm{X}_{7}\right)$ had negative sign but significant at the $5 \%$ level on maize production. Its significance at the $5 \%$ suggests that it contributed to small-scale farmers' maize production by having a considerable effect. Considering the magnitude of the coefficients of Educational level $\left(\mathrm{X}_{7}\right)$ to other coefficients, it is possible to argue that, this variable had contributed less in maize production than other significant variables. In the same line of thinking, both variables Seeds $\left(\mathrm{X}_{3}\right)$, Irrigation $\left(\mathrm{X}_{5}\right)$ and Organic manure $\left(\mathrm{X}_{9}\right)$ have had negative signs and were not significant, although being important in maize production process (Olarinde, 2011; Ferdausi et al., 2014; Mango et al, 2015; Shehu et al, 2017). This result suggests that the three variables did not contribute to small-scale farmers' maize production by having significant effects. The results also indicated that variables Land (X1), Labour $\left(\mathrm{X}_{2}\right)$, Soil were all positive and significant effects at the $1 \%$ and $5 \%$ respectively. The regression results for efficient use of resources are presented in Table 2.

Table 2. Regression results for small-scale farmers maize production in Mwanza

\begin{tabular}{lcccc}
\hline Variable & $\begin{array}{c}\text { Coefficient } \\
(\mathrm{B})\end{array}$ & $\begin{array}{c}\text { Std. } \\
\text { Error }\end{array}$ & $\mathrm{t}$ - value & P - value \\
\hline Constant & 4.325 & 0.065 & 4.041 & 0.236 \\
Land (ln X1) & 1.432 & 0.016 & $-1.310^{*}$ & 0.029 \\
Labour (ln X2) & 1.251 & 0.018 & $3.262^{*}$ & 0.008 \\
Seeds (ln X3) & -0.122 & 0.026 & -0.019 & 0.006 \\
Soil preparation (ln X4) & 0.238 & 0.008 & $0.217^{* *}$ & 0.004 \\
Irrigation (ln X5) & -0.104 & 0.016 & -0.003 & 0.035 \\
Age (ln X6) & 1.407 & 0.008 & $25.409^{*}$ & 0.010 \\
Educational level (ln X7) & -0.205 & 0.006 & $-22.028^{*}$ & 0.016 \\
Experience (ln X8) & 0.239 & 0.011 & $5.224^{*}$ & 0.133 \\
Organic manure (ln X9) & -0.038 & 0.023 & -0.002 & 0.342 \\
\hline
\end{tabular}

Source: Research data, 2020. $\mathrm{R}^{2}=0.77 ;{ }^{* * *} \mathrm{p} \leq 0.01(1 \%) ; * * \mathrm{p} \leq 0.05(5 \%)$; Return to scale $\mathrm{r}=1.498$.

This indicates that they played significant role in small-scale maize production. It also indicated that there was a positive correlation between these variables and maize production. Comparing the coefficients of these five variables, variable Age $\left(\mathrm{X}_{6}\right)$ seems to have contributed more to the production process of maize by small-scale farmers, followed by variable labour. Therefore, the lead equation is thus presented as given below in equation (4): 


$$
\begin{aligned}
\text { Lit } Y=4.325 & +1.432 X_{1}+1.251 X_{2}+0.238 X_{4}+1.407 X_{6}-0.205 X_{7} \\
& +0.239 X_{8} \ldots \ldots . . .(4)
\end{aligned}
$$

The level of maize output produced will vary with variation in land size, labour, soil preparation, age of the farmer, and experience in farming to some extent.

However, the coefficient of variable experience, although small compared to the coefficients of variables Labour and Age, it is often a very important factor in agricultural production process, because production without experience leads to nothing (Abdulai et al,. 2018). As far as the production of maize by small-scale farmers was concerned; the total sum of $\beta_{1}+\beta_{2}+\ldots . \beta 9$ of the inputs used was (1.498) and was greater than one. This value indicates that small-scale farmers in the study area operate under increasing returns to scale $(r<1)$. That is, resources were over utilized, that is, which suggests a sign of inefficiency, meaning that the output (profit) can be increased only by decreasing the quantity of resources used, given appropriate technology and know-how. When the ration is $r>1$, it indicates underutilization of resources which is also a sign of inefficiency. It means that by increasing the rate of use of the resources can lead to increase the level of output (profit), given appropriate technology and know-how. When the ratio is $r=0$, it indicates efficiency in the use of resources.

As it can be noticed, all the coefficients in the model for productive factors (land, labour, soil preparation, age, and experience) were positive, with exception of the coefficient of educational level which was negative. The coefficients were significant at $1 \%$ and $5 \%$ respectively. For instance, the coefficient for labour of 1.251 indicates that maize output is elastic to changes in labour. A $1 \%$ increase in labour (person/ day) will induce about $12,51 \%$ increase in maize output. This result is consistent with the findings of Mango at al., (2015). Since small-scale farmers experience resource-constraints, labour is important for maize output. Given that maize production is labour-intensive, they can rely more on manual labour for their outputs (Abdulai et al., 2018). The coefficient for land used in maize production was positive 1.432 and significant at the $1 \%$. It suggested that a $1 \%$ increase in area cultivated would induce $14.32 \%$ change in maize output. This is not surprising given that land is a significant factor in maize production output. This funding is consistent with those of McKay et al., (1999) and Skarstein (2005). Lastly, the coefficient of determination $\mathrm{R}^{2}$ was 0.77 , indicating that about $77 \%$ of variations in maize production has been explained by the explanatory variables of the model. In terms of production constraints, it was noticed that most farmers, about $96 \%$ indicated that extension services, fertilizer and finance were the main constraint to maize farming (Table 3). 
Table 3. Main constraints to maize production by small-scale farmers

\begin{tabular}{ccc}
\hline Constraints & Frequency & Percentage \\
\hline Extension services & 70 & 97 \\
Fertilizer / manure & 68 & 94 \\
Finance & 53 & 74 \\
Access to land & 24 & 33 \\
Other & 12 & 17 \\
\hline
\end{tabular}

Source: Research data, 2020.

In line with Table 3, about $97 \%$ of respondents expressed the need for extension services, $94 \%$ said they wanted to be assisted with fertilizer, $74 \%$ wanted finance, $33 \%$ needed access to farming land, and the remaining $17 \%$ were classified as other needs.

\section{Conclusions and Recommendations}

\subsection{Conclusions}

The aim of this study was to investigate efficient use of resources in maize production by small-scale producers in Mwanza. The research design followed both qualitative and quantitative design using both secondary and primary data collected from 72 participants. Secondary data was gathered from various official reports while primary data was collected from a cross-sectional survey of maize production in the region. A Cobb-Douglas production function in its linear form was utilized to analyze the data. The analysis showed that the sum of inputs used was (1.498) being greater than 1. It suggested that there was an overutilization of resources (not efficient utilization) which did not lead to optimum economic gains by farmers. This situation indicated misuse of scarce resources with decreases in output, while maize production being negatively affected, with far reaching implications for food production in the region (Gani \& Omonona, 2009). The policy implications for these findings are that resources use efficiency in small-scale farmers maize production could be normalized through better strategies leading to know-how in the use of scarce available inputs, given the current state of technology. This could be achieved through improving farmer-specific efficiency in the use of production factors. This also includes more exposure of small-scale farmers to frequent extension services, land sizes and other needs in maize production (Mango et al., 2015). Regional government could assist in the improvement of efficiency of the small-scale maize producers, who contribute more than $80 \%$ of national output (FAO, 2015), by ensuring better and more reliable support from extension services and also by encouraging and supporting women small-scale maize farmers in the region.

The study, however, did only investigate resource use efficiency of small-scale maize production in three villages at one point in time. Given the importance of maize as the main staple food crop, increasing its production will ensure food security in both rural and urban communities to some extent. For this to happen, small-scale farmers will be required to operate as efficiently as possible, with the available inputs. Results from the analysis can help 
contribute to the various ways of finding solutions in increasing maize production that has remained the same or fallen due to inefficient production processes. This should be the target of policy aimed at improving the productivity of the maize in the study area. Continuous improvement in resource use efficiency in maize production is needed to promote income growth of small-scale farmers and reduce poverty (Ferdausi et al., 2014; Mango et al., 2015; Memon et al., 2016; Shehu et al., 2017)

\subsection{Recommendations}

In line with the findings of the study, it is possible to recommend the following: in order for small-scale maize producers to produce efficiently, they need to be assisted with productive inputs as well extension service to guide them on how to use the inputs. They need to be trained on how to be efficient in increasing the output. Although this study examined un number of factors that were hypothesized to affect small-scale farmers maize production in Mwanza, further studies should be conducted to identify other socio-economic factors that may also affect the production of other agricultural crops by small-scale farmers in the country.

\section{References}

Abdulai, S., Nkegbe, P. K., \& Donkoh, S. A. (2018). Assessing the technical efficiency of maize production in northern Ghana: The data envelopment analysis approach. Cogent Food \& Agriculture, 4(1), 1-14. https://doi.org/10.1080/23311932.2018.1512390

Adebowale, S. (2014). Agricultures contribution to Nigeria's economy in 2012. Retrieved from

http://www.theageonline.com.ng/agriculture-contributed-n348-7b-nigerias-economy-2012-re port

Astalin, P. K. (2013). Qualitative research design: A Conceptual Framework. International Journal of Social Science and Interdisciplinary, 2(1), 118-124.

Corbin, J., \& Strauss, A. (2008). Basics of Qualitative Research: Techniques and Procedures for Developing Grounded Theory (3rd ed.). Thousand Oaks, CA: SAGE Publications

FAO. (2015). The MAIZE Value Chain in Tanzania A report from the Southern Highlands Food Systems Programme. Retrieved from http://www.fao.org/fileadmin/user_upload/ivc/PDF/SFVC/ Tanzania_maize.pdf

Ferdausi, S., Islam, M. S., Khatun, M. A., \& Islam, M. M. (2014). An economic study on maize production in some selected areas of Bogra District. Retrieved from https://www.researchgate.net/publication/332343729_An_Economic_Study_on_Maize_Prod uction_in_Some_Selected_Areas

Gani, B. S., \& Omonona, B. T. (2009). Resources use efficiency among small scale irrigation Maize producers in Northern Taraba State of Nigeria. Journal of Hum Ecology, 28(2), 113-119.

Gujarati, D. N. (2006). Basic Econometrics (2nd ed.). New York: Bernard M. Baruch College. 
Mango, N., Makate, C., Hanyani-Mlambo, B., Siziba, S., \& Lundy, M. (2015). A stochastic frontier analysis of technical efficiency in smallholder maize production in Zimbabwe: The post-fast-track land reform outlook. Cogent Economics \& Finance, Abingdon, 3(1), 1-14. http://dx.doi.org/10.1080/23322039.2015.1117189.pdf

Match Maker Association. (2014). Maize sector in Tanzania: challenges and opportunities. Retrieved from https://www.matchmakergroup.com/news/maize-sector-in-tanzania-challenges-and-opportuni ties.aspx\#.XpMB10AzbIU

McKay, A., Morrissey, O., \& Vaillant, C. (1999). Aggregate Agricultural Supply Response in Tanzania. Journal of International Trade and Economic Development, 8(1), 107-123.

Memon, N., Noonari, S., Wagan, H., Lakhio, M. H., \& Wakeel, A. (2016). Analysis on Technical Efficiency of Hybrid Maize Production in District Mirpurkhas, Sindh. Management and Organizational Studies, 3(2), 30-38. https://doi.org/10.5430/mos.v3n2p30

Olarinde, L. O. (2011). Analysis of Technical Efficiency Differentials among Maize Farmers in Nigeria. AERC Research Paper 232. African Economic Research Consortium, Nairobi January. Retrieved from https://aercafrica.org/wp-content/uploads/2018/07/RP232.pdf

Shehu, U. A., Ibrahim, A. I., Hassan, T., \& Bello, M. (2017). Analysis of Resource Use Efficiency in Small-Scale Maize Production in Tafawa-Balewa Local Government of Bauchi State Nigeria. Journal of Agriculture and Veterinary Science, 10(1), 59-65. https://doi.org/10.9790/2380-1001015965

Skarstein, R. (2005), Economic Liberalisation and Smallholder Productivity in Tanzania: From Promised Success to Real failure, 1985-1998. Journal of Agrarian Change, 5(3), 334-362.

Tambo, J. A., \& Gbemu, T. (2010). Resource-use efficiency in Tomato in Ghana Production in the Dangme West District, Ghana. Conference on International Research on Food Security. Tomato from related wild nightshades.

Undie, U. L., Uwah, D. F., \& Attoe, E. E. (2012). Effect of intercropping and crop arrangement on yield and productivity of late season Maize/soybean mixtures in the humid environment of South Southern Nigeria. Journal of Agricultural Science, 4(4), 37-50. http:dx.doi.org/10.5539/jas.v4n4p37

URT. (1999). Mwanza Region Socio-Economic Profile. Joint Publication by: The Planning Commission Dar es Salaam and Regional Commissioner's Office Mwanza. Rolling Plan and forward Budget 1996/97 - 1998/99, Mwanza Region. The United Republic of Tanzania. Retrieved from http://www.tzonline.org/pdf/Mwanza.pdf

URT. (2013). 2012 Population and housing census - Population Distribution by Administrative Areas. National Bureau of Statistics Ministry of Finance Dar es Salaam and Office of Chief Government Statistician, President's Office. The United Republic of Tanzania. Retrieved from http://www.tzdpg.or.tz/fileadmin/documents/dpg_internal/dpg.pdf 


\section{Macrothink}

International Journal of Regional Development

ISSN 2373-9851 2020, Vol. 7, No. 1

World Bank. (2015). Agriculture global practice technical assistance Paper. Tanzania Agricultural Sector Risk Assessment World Bank Group Report Number 94883-TZ June. Retrieved from http://documents.worldbank.org/curated/en/248961468001158010/pdf/94883-Revised-Box39 3201B-Public-Tanzania-Ag-Risk-Assessment-web-6-29-15-JK-jtc.pdf

\section{Copyright Disclaimer}

Copyright for this article is retained by the author(s), with first publication rights granted to the journal.

This is an open-access article distributed under the terms and conditions of the Creative Commons Attribution license (http://creativecommons.org/licenses/by/3.0/). 